\title{
Factors Responsible for Diabetes Neuropathy among Bangladeshi Adults
}

\author{
K.C. Bhuyan \\ Department of Statistics, Jahangirnagar University, Savar, Bangladesh
}

*Corresponding Author: K.C. Bhuyan, Department of Statistics, Jahangirnagar University, Savar, Bangladesh. Email: kcbhuyan2002@yahooo.com

\begin{abstract}
The information presented here were the analytical results observed from 960 adults residing in both urban and rural areas of Bangladesh. The adults were investigated by some doctors and nurses according to convenience and quota sampling plan. In the sample, $16.1 \%$ adults were suffering simultaneously form diabetes and neuropathy. Among the investigated adults $43.5 \%$ were from rural areas and prevalence of diabetic neuropathy was noted among $16.3 \%$ of them. The prevalence rates were 17.1, 16.9, 17.8, 20.5, 19.3, 22.7, 28.4 and 17.6, respectively among males, married persons, Muslim adults, adults of ages 30 - 50 years, secondary educated adults, farmers and unskilled labours, respondents from lowest family expenditure group of families and adults habituated in taking restaurant food. All categories of these respondents were more exposed to the prevalence of diabetes and neuropathy. Level of obesity was significantly associated with the prevalence of the disease under study, but overweight and obese persons were less affected $(11.2 \%)$ by this health hazard. The most responsible variable for the prevalence of simultaneous diabetes and neuropathy was occupation followed by over age, physical inactivity, smoking habit, hypertension, body mass index and lower economic status. These variables were identified by factor analysis.
\end{abstract}

Keywords: Diabetes, Neuropathy, Association, Odds ratio, Factor analysis, Communality and Factor loadings.

\section{INTRODUCTION}

Diabetic neuropathy is a common physical disorder, especially among diabetic patients. It was reported that in Bangladesh it affected 90\% of the diabetic patients [1]. It is the most common form of neuropathy in the Western world and one of the most common diabetic complications [2]. The rate of prevalence of the problem was $4.3 \%$ in 2006 in India compared to 1 to 2 per cent in western world [3]. The impacts of this prevalence are great morbidity, mortality, sleep apnea, lower limb amputation and great economic burden [2 - 9]. The problem is predominant among females and older people [10]. It is also predominant among diabetic patients suffering for longer duration [11]. Besides these, the other responsible factors of the prevalence of the disease [2] are height, hyperglycemia, hypertension, waist circumference and obesity.

The objective of the present work was to explore some of the demographic variables responsible for the prevalence and nonprevalence of diabetic neuropathy among adults in Bangladesh.

\section{Methodology}

For the present analysis the data were recorded from urban and rural adults of ages 18 years and above by quota sampling plan to cover $70 \%$ diabetic patients so that sufficient number of adults suffering from different diseases originated from diabetes and obesity would be included in the sample [12]. During investigation data were recorded from 960 adults of ages 18 years and above living in both urban and rural areas of Bangladesh. These adults were interviewed by some doctors and nurses according to their convenience from and nearby their working places. Data were recorded from respondents through a pre-designed and pre-tested questionnaire. Maximum questions in the questionnaire were incorporated to collect demographic and social information of the respondents themselves including their blood pressure, prevalence of any other health hazard, physical activity and their lifestyle. Information of monthly family income and family expenditure (in 000 taka) were also recorded. The value of each of the variable was noted in nominal scale. The data of weight (in $\mathrm{kg}$ ) 
divided by Height (in metre ${ }^{2}$ ) was used to measure the value of body mass index (BMI). The investigated subjects were classified into 4 classes, viz. underweight ( if BMI $<20$ ), normal ( $20<\mathrm{BMI},<25$ ), overweight ( $25<$ BMI $<30$ ) and obese ( BMI $\geq 30$ ) [ 13 ]. They were also divided into 4 groups according to their blood pressure level ( $\mathrm{mmHg}$ ). The 4 groups were identified as optimal ( $\mathrm{BP}<$ $120 / 80$ ), normal (BP <130/85), high normal $(\mathrm{BP}<140 / 85)$ and hypertensive ( $\mathrm{BP} \geq 140 / 90)$ [14].

According to the objective of the study, association of any of the socioeconomic characteristics with level of blood pressure was examined. Significant association was decided if p-value of any Chi-square test statistic was $\leq$ 0.05 . The odds ratio $[O . R]$ in favour of a higher group (in percentage) of any demographic characteristic was calculated. Factor analysis was done to identify responsible variables for the prevalence of the disease. The analysis was done using SPSS version 25.

\section{ReSUlts}

Out of 960 adults $66.9 \%$ were diabetic and prevalence of neuropathy was noted among $24.1 \%$ of them [Table 1].

Table1. Distribution of adults according to prevalence of diabetes and neuropathy

\begin{tabular}{|l|c|c|c|c|c|c|}
\hline \multirow{3}{*}{ Prevalence of diabetes } & \multicolumn{3}{|c|}{ Prevalence of Neuropathy } & \multicolumn{2}{c|}{ Total } \\
\cline { 2 - 7 } & \multicolumn{2}{|c|}{ Yes } & \multicolumn{2}{c|}{ No } & N & $\%$ \\
\cline { 2 - 7 } & $\mathrm{N}$ & $\%$ & $\mathrm{~N}$ & $\%$ & 642 & 66.9 \\
\hline Yes & 155 & 24.1 & 487 & 75.9 & 318 & 33.1 \\
\hline No & 0 & 0.0 & 318 & 100.0 & 960 & 100.0 \\
\hline Total & 155 & 16.1 & 805 & 83.9 & \\
\hline
\end{tabular}

No non-diabetic patient was suffering from neuropathy. Prevalence of diabetes and prevalence of diabetes neuropathy were significantly associated $\left[\chi^{2}=91.559, \mathrm{p}\right.$-value $=$ $0.000]$. The percentage of rural adults was 43.5 and $16.3 \%$ of them were suffering from diabetes neuropathy .This percentage was slightly less (16.1\%) among urban adults. But urban and rural adults were similarly exposed to this health problem [Table 2; O.R.= 1.02, S.E $\{\ln$ O.R $)=$ $0.18\}, \chi^{2}=0.008, \mathrm{p}$-value $\left.=0.928\right]$. In the sample there were $55.2 \%$ male respondents and among $17.0 \%$ of them the prevalence of diabetes neuropathy was noted. However, the prevalence rate was not associated with sex $\left[\chi^{2}=0.610, \mathrm{p}-\right.$ value $=0.485]$. However, the chance of male to be affected by the problem was 1.15 times compared to that of female $[$ O.R. $=1.15$, $\mathrm{S} . \mathrm{E}\{\ln ($ O.R. $)\}=0.18]$.

The Muslim respondents (82.6\%) had 2.36 times chance to be affected by this health hazard as it was for non-Muslim adults. The prevalence rate $(17.8 \%)$ among Muslim was more than double compared to their non-Muslim counterpart $(8.4 \%)$. This differential was highly significant $\quad\left[\quad \chi^{2}=8.998, \quad \mathrm{p}\right.$-value $=0.003$; O.R.=2.36, S.E $\{\ln ($ O.R. $)\}=0.29]$. The chance of prevalence of the problem among married persons was 1.20 times as it was in single adults [ O.R.-1.20, S.E. $\{\ln ($ O.R. $)\}=0.20$ ]. But prevalence of diabetes neuropathy was not significantly associated with marital status $\left[\chi^{2}\right.$
$=0.849, \mathrm{p}$-value $=0.357 \mathrm{]}$, though prevalence rate $(16.9 \%)$ was more among married adults $(69.8 \%)$ compared to that of single adults (14.5\%). Secondary educated adults were $23.9 \%, 21.0 \%$ of them were facing the simultaneous problem of diabetes and neuropathy. They were $1.47 \%$ times more exposed to the problem of this health hazard [O.R. $=2.47$, S.E. $\{\quad \ln ($ O.R. $)\}=0.0 .21]$. The prevalence rate was significantly associated with diabetes neuropathy $\left[\chi^{2}=8.158, \quad \mathrm{p}\right.$ value $=0.043]$. The rates were in decreasing trend with the increase in level of education. Significant decreasing trend [ $\chi^{2}=11.277, \mathrm{p}$ value $=0.010]$ in rates of this health hazard was also noted with the increase in white collar job. The rates were lower among servicemen (13.1\%) and businessmen (13.7\%). Surprisingly enough, this prevalence rate $(22.7 \%)$ was very high among farmers and unskilled labours. In the sample they were $26.6 \%$. This group was $17 \%$ more exposed to this health hazard [ O.R.= 1.17;S.E $\{\ln ($ O.R. $)\}=0.23$ ]. This group was doing physical labour, but still they were more exposed to this health problem. Similar was the case with adults doing physical work (36.6\%). They were more exposed by $31 \%$ [ O.R. $=1.31$, S.E $\{\ln ($ O.R. $)\}=0.18$ ], though involvement in physical labour was independent of prevalence of diabetes neuropathy $\left[\chi^{2}=2.301, \mathrm{p}\right.$ value $=0.129]$. The percentage of adults who did some physical work, $18.5 \%$ of them had this health problem. The corresponding percentage 
Factors Responsible for Diabetes Neuropathy among Bangladeshi Adults

among adults who did not do any physical labour was 14.8. The prevalence rate of diabetes neuropathy was not significantly increased $\left[\chi^{2}\right.$ $=8.665$, $\mathrm{p}$-value $=0.070]$ with age .

Table2. Distribution of adults according to socioeconomic characteristics and prevalence of diabetes neuropathy

\begin{tabular}{|c|c|c|c|c|c|c|}
\hline \multirow{3}{*}{ Socioeconomic characteristics } & \multicolumn{4}{|c|}{ Prevalence of diabetes neuropathy } & \multirow{2}{*}{\multicolumn{2}{|c|}{ Total }} \\
\hline & \multicolumn{2}{|c|}{ Yes } & \multicolumn{2}{|c|}{ No } & & \\
\hline & $\mathrm{N}$ & $\%$ & $\mathrm{~N}$ & $\%$ & $\mathrm{~N}$ & $\%$ \\
\hline \multicolumn{7}{|l|}{ Residence } \\
\hline Rural & 68 & 16.3 & 350 & 83.7 & 418 & 43.5 \\
\hline Urban & 87 & 16.1 & 455 & 83.9 & 542 & 56.5 \\
\hline Total & 155 & 16.1 & 805 & 83.9 & 960 & 100.0 \\
\hline \multicolumn{7}{|l|}{ Gender } \\
\hline Male & 90 & 17.0 & 440 & 87.0 & 530 & 55.2 \\
\hline Female & 65 & 15.1 & 365 & 84.9 & 430 & 44.8 \\
\hline \multicolumn{7}{|l|}{ Religion } \\
\hline Muslim & 141 & 17.8 & 652 & 82.2 & 793 & 82.6 \\
\hline Non-Muslim & 14 & 8.4 & 153 & 91.6 & 167 & 17.4 \\
\hline \multicolumn{7}{|l|}{ Marital status } \\
\hline Currently married & 113 & 16.9 & 557 & 83.1 & 670 & 69.8 \\
\hline Currently single & 42 & 14.5 & 248 & 85.5 & 290 & 30.2 \\
\hline \multicolumn{7}{|l|}{ Age ( in years) } \\
\hline$<20$ & 4 & 14.3 & 24 & 85.7 & 28 & 2.9 \\
\hline $20-30$ & 19 & 11.7 & 143 & 88.3 & 162 & 16.9 \\
\hline $30-40$ & 45 & 18.0 & 205 & 82.0 & 250 & 26.0 \\
\hline $40-50$ & 54 & 20.5 & 210 & 79.5 & 264 & 27.5 \\
\hline $50^{+}$ & 33 & 12.9 & 213 & 87.1 & 256 & 26.7 \\
\hline \multicolumn{7}{|l|}{ Education } \\
\hline Illiterate & 10 & 18.5 & 44 & 81.5 & 54 & 5.6 \\
\hline Primary & 22 & 19.1 & 93 & 80.9 & 115 & 12.0 \\
\hline Secondary & 48 & 21.0 & 181 & 79.0 & 229 & 23.9 \\
\hline Higher & 75 & 13.3 & 487 & 86.7 & 562 & 58.5 \\
\hline \multicolumn{7}{|l|}{ Occupation } \\
\hline Agriculture and unskilled labor & 58 & 22.7 & 197 & 77.3 & 255 & 26.6 \\
\hline Business and skilled labor & 22 & 13.7 & 139 & 86.3 & 161 & 16.8 \\
\hline Service & 28 & 13.1 & 185 & 86.9 & 213 & 22.2 \\
\hline Housewives, students and unemployed & 47 & 14.2 & 284 & 85.8 & 331 & 34.5 \\
\hline \multicolumn{7}{|l|}{ Income ( in 000 taka) } \\
\hline$<40$ & 70 & 22.5 & 241 & 77.5 & 311 & 32.4 \\
\hline $40-60$ & 23 & 12.2 & 166 & 87.8 & 189 & 19.7 \\
\hline $60-80$ & 25 & 13.3 & 163 & 86.7 & 188 & 19.6 \\
\hline $80-100$ & 24 & 15.0 & 136 & 85.0 & 160 & 16.7 \\
\hline $100^{+}$ & 13 & 11.6 & 99 & 88.4 & 112 & 11.7 \\
\hline \multicolumn{7}{|l|}{ Smoking habit } \\
\hline Yes & 61 & 16.4 & 312 & 83.6 & 373 & 38.9 \\
\hline No & 94 & 16.0 & 493 & 84.0 & 587 & 61.1 \\
\hline \multicolumn{7}{|l|}{ Family expenditure ( in 000 taka) } \\
\hline$<30$ & 33 & 28.4 & 83 & 71.6 & 116 & 12.1 \\
\hline $30-50$ & 52 & 17.6 & 243 & 82.4 & 295 & 30.7 \\
\hline $50-70$ & 26 & 12.5 & 182 & 87.5 & 208 & 21.7 \\
\hline $70-90$ & 26 & 14.7 & 51 & 85.3 & 177 & 18.4 \\
\hline $90^{+}$ & 18 & 11.0 & 146 & 89.0 & 164 & 17.1 \\
\hline \multicolumn{7}{|l|}{ Taking restaurant food } \\
\hline Yes & 87 & 17.6 & 106 & 82.4 & 493 & 51.4 \\
\hline No & 68 & 14.6 & 399 & 85.4 & 467 & 48.6 \\
\hline \multicolumn{7}{|l|}{ Use of can food } \\
\hline Yes & 92 & 15.8 & 492 & 84.2 & 584 & 60.8 \\
\hline No & 63 & 16.8 & 313 & 83.2 & 376 & 39.2 \\
\hline
\end{tabular}




\begin{tabular}{|c|c|c|c|c|c|c|}
\hline \multicolumn{7}{|l|}{ Physical work } \\
\hline Yes & 65 & 18.5 & 286 & 81.5 & 318 & 36.6 \\
\hline No & 90 & 14.8 & 519 & 85.2 & 609 & 63.4 \\
\hline \multicolumn{7}{|l|}{ Utilization of time } \\
\hline Read and use mobile phone & 13 & 9.4 & 126 & 90.6 & 139 & 14.5 \\
\hline Play and use mobile phone & 46 & 19.1 & 195 & 80.9 & 241 & 25.1 \\
\hline Do household work and watch T.V. & 54 & 21.9 & 193 & 78.1 & 247 & 25.7 \\
\hline $\begin{array}{l}\text { Read paper and use mobile phone after } \\
\text { office work }\end{array}$ & 41 & 16.5 & 208 & 83.5 & 249 & 25.9 \\
\hline $\begin{array}{l}\text { Watch T.V. and use mobile phone after } \\
\text { office work }\end{array}$ & 1 & 1.2 & 83 & 98.2 & 84 & 8.8 \\
\hline \multicolumn{7}{|l|}{\begin{tabular}{|l|} 
Level of Obesity \\
\end{tabular}} \\
\hline Under weight & 17 & 20.0 & 68 & 80.0 & 85 & 8.9 \\
\hline Normal weight & 91 & 20.0 & 365 & 80.0 & 456 & 47.5 \\
\hline Overweight & 37 & 11.3 & 290 & 88.7 & 327 & 34.1 \\
\hline Obese & 10 & 10.3 & 82 & 89.7 & 92 & 9.6 \\
\hline \multicolumn{7}{|l|}{ Level of hypertension } \\
\hline Optimal & 66 & 15.1 & 370 & 84.9 & 436 & 45.4 \\
\hline Normal & 71 & 18.7 & 308 & 81.3 & 379 & 39.5 \\
\hline High Normal & 17 & 18.9 & 73 & 81.1 & 90 & 9.4 \\
\hline Hypertensive & 1 & 1.8 & 54 & 98.2 & 55 & 5.7 \\
\hline \multicolumn{7}{|l|}{ Duration of Disease ( in years) } \\
\hline 0 & 150 & 18.6 & 658 & 81.4 & 808 & 84.2 \\
\hline$<1$ & 1 & 3.6 & 27 & 96.4 & 28 & 2.9 \\
\hline $1-3$ & 3 & 4.8 & 59 & 95.2 & 62 & 6.5 \\
\hline $3-5$ & 0 & 0.0 & 32 & 100.0 & 32 & 3.3 \\
\hline $5+$ & 1 & 3.3 & 29 & 96.7 & 30 & 3.1 \\
\hline Total & 155 & 16.1 & 805 & 83.9 & 960 & 100.0 \\
\hline
\end{tabular}

But adults of ages 30 to 50 years were $66 \%$ more exposed $[\mathrm{R} . \mathrm{R}=1.66, \mathrm{~S}, \mathrm{R} .\{\ln (\mathrm{O} . \mathrm{R})\}=$. $0.18]$ to this health problem. In the sample, they were $53.5 \%$ and $19.0 \%$ of them were patients of diabetes neuropathy as against the overall 16.1 $\%$ patients of this category.

The percentage of adults of lowest income was 32.4 and $22.5 \%$ of them were patients of diabetes neuropathy. Lowest rate $(11.6 \%)$ of this type of patients was noted in the families of highest income group (11.7\%). The differences in proportions of diabetes neuropathy patients in families of different levels of income were significant [ $\chi^{2}=14.491, \mathrm{p}$ - value $=0.006$ ]. Lowest income group of adults was $93 \%$ more exposed to this health problem [ R.R.=1.93, S.E. $\{\ln ($ O.R $)\}=0.18$ ]. Lowest family expenditure was also the risk factor for adults to be affected by this disease [ O.R. $=2.35$, S.E. $\{\ln ($ O.R $)\}=023]$.

It was observed that only $12.1 \%$ adults had lowest family expenditure and $28.4 \%$ of them were suffering from this disease. There was a decreasing trend of prevalence rate of the disease with the increase in family expenditure [ $\chi^{2}=19.003$, $\mathrm{p}$ value $\left.=0.001\right]$.

Habit of taking restaurant food and can food were not associated with the prevalence of diabetes neuropathy $\left[\chi^{2}=1.687, \mathrm{p}-\right.$ value $=$ $0.194 ; \quad \chi^{2}=0.170, \mathrm{p}$ value $=0.880$, respectively]. However, habituated in restaurant food created 1.26 times risk to this health problem for $51.4 \%$ adults and already [O.R. $=1.26$, S.E. $\{\ln ($ O.R. $)\}=0.18] 17.6 \%$ of them were suffering from diabetes neuropathy. The percentage of can food users was 60.8 but $15.8 \%$ of them were experienced of this health hazard as against $16.8 \%$ of their counterpart. However, habit of taking can food was not the risk factor for the prevalence of diabetes neuropathy [ O.R. $=1.08$, S.E. $\{\ln ($ O.R. $)\}=0.18$ ].

Level of obesity was significantly associated with prevalence of diabetes neuropathy but it was amazing that the prevalence rates were higher $(20.0 \%$ in each case) among both underweight $(8.9 \%)$ and normal group $(47.5 \%)$. Significant $\left[\chi^{2}=13.551, \mathrm{p}\right.$-value $=0.004$ ] decreasing trend of prevalence rate was noted among overweight $(34.1 \%)$ and obese group of adults $(9.6 \%)$. The affected adults in these two groups were $11.3 \%$ and $10.3 \%$, respectively. The chance to be affected by this health problem was 1.97 times for adults having lower level of BMI [ O.R. $=1.97$, S.E. $\{\ln ($ O.R $)\}=0.19$ ].

Level of hypertension was significantly associated $\left[\chi^{2}=11.041, \mathrm{p}\right.$ value $\left.=0.012\right]$ with 
the prevalence of diabetes neuropathy and adults including normal, high normal and hypertensive group was $15 \%$ more exposed to this health hazard [ O.R. $=1.15$, S.E. $\{\ln ($ O.R. $)\}=0.18\}$ ]. A big group of adults (45.4\%) were of optimal blood pressure and $15.1 \%$ of them were suffering from this health problem as against $16.1 \%$ sufferers in the sample.

Duration of diseases was a significant factor for the $\left[\chi^{2}=22.415\right.$, $\mathrm{p}$-value $\left.=0.000\right]$ prevalence of diabetes neuropathy though only 5 adults were suffering for more times. These 5 patients were not really exposed to this health problem

$$
\text { [ O.R. }=0.15 \text {, S.E. }\{\ln (\text { O.R. })\} 0.46 \text { ]. }
$$

It was noted that $34.7 \%$ adults were involved in sedentary activities but only $12.6 \%$ of them were affected by this health hazard and they were less exposed to the prevalence of diabetes neuropathy [O.R $=0.66, \mathrm{~S} . \mathrm{E}\{\ln (\mathrm{O} . \mathrm{R})\}=0.20$.$] .$ However, there was significant association between utilization of time and prevalence of diabetes neuropathy $\left[\chi^{2}=26.135, \quad \mathrm{p}\right.$ value $=0.000]$.

\subsection{Factor Analysis}

As per objective of the study, attempt was made to identify some of the socioeconomic characteristics enhancing the prevalence of diabetes neuropathy among adults. The identification was done by factor analysis. The variables included for the analysis were residence, religion, gender, marital status, age, education, occupation, income, expenditure, body mass index, level of hypertension, habit of taking restaurant food and can food, smoking habit, physical activity and utilization of time by the respondents. Though the inclusion of the variables was not significant $[\mathrm{KMO}=186.157$, $\mathrm{F}=1.158$, $\mathrm{p}$-value $=0.252 \mathrm{]}$, still some variables were identified as responsible for the prevalence of the disease. The identification was done using the higher absolute value of the factor loadings [ 15,16$]$. The results of the analysis were presented in Table 3.

Table3. Results of factor analysis

\begin{tabular}{|c|c|c|c|c|}
\hline Variable & \multirow{2}{*}{ Communality } & \multicolumn{3}{|c|}{ Coefficient of } \\
\cline { 3 - 5 } & & Factor - 1 & Factor-2 & Factor -3 \\
\hline Residence & 0.486 & 0.080 & 0.578 & 0.384 \\
\hline Religion & 0.985 & -0.334 & -0.930 & 0.097 \\
\hline Gender & 0.394 & 0.348 & -0.432 & 0.394 \\
\hline Age & 0.944 & 0.937 & 0.257 & 0.018 \\
\hline Marital status & 0.985 & -0.334 & -0.930 & 0.097 \\
\hline Education & 0.953 & -0.582 & 0.511 & 0.595 \\
\hline Occupation & 0.995 & 0.981 & 0.065 & -0.165 \\
\hline Income & 0.959 & -0.710 & 0.671 & -0.074 \\
\hline Expenditure & 0.978 & -0.732 & 0.654 & -0.120 \\
\hline Body mass index & 1.000 & 0.745 & 0.355 & -0.458 \\
\hline Utilization of time & 0.935 & -0.129 & 0.911 & -0.297 \\
\hline Habit of taking restaurant food & 0.698 & 0.042 & -0.777 & -0.303 \\
\hline Habit of taking can food & 0.944 & 0.525 & 0.177 & 0.89 \\
\hline Physical labour & 0.999 & -0.936 & -0.309 & 0.168 \\
\hline Duration of disease & 0.989 & 0.301 & 0.231 & 0.920 \\
\hline Hypertension & 0.968 & 0.777 & -0.546 & 0.251 \\
\hline Smoking habit & 0.999 & 0.936 & 0.309 & -0.168 \\
\hline
\end{tabular}

It was seen that the most responsible variable was occupation followed by age, physical labour, smoking habit, hypertension, body mass index, and family expenditure.

\section{DISCUSSION}

Except clinical and subclinical aspects, some of the demographic characteristics are responsible for the prevalence of diabetes neuropathy $[1,8$, 9]. Accordingly, an attempt was made to identify the most responsible variable for this health hazard. To fulfil the objective, the analysis was done using the collected data of
960 adults of ages 18 years and above. The adults were interviewed by some doctors and nurses using quota sampling plan to cover $70 \%$ diabetic patients so that the sample would contain sufficient number of adults of diabetes and patients of diabetes related diseases simultaneously.

The analysis showed that males, married adults, Muslim respondents, illiterate persons, and physically inactive persons were more exposed to the simultaneous problem of diabetes and neuropathy. In earlier studies, it was observed that diabetes was pre-dominant among these 
adults [17 - 20]. This analysis indicated that prevalence of diabetes and prevalence of neuropathy was significantly associated. In many studies it was noted that age was the risk factor for diabetes and its related diseases [ 21 24 ]. This study showed significant association between age and prevalence of diabetes neuropathy. But majority adults of ages 30-50 years were more exposed to this health hazard. Family higher economic condition was the risk factor for diabetes [ 17, 20, 23 ]. But this study showed the evidence that lower level of family economy was the cause of prevalence of diabetes neuropathy. In earlier studies it was reported that obesity was one of the cause of prevalence of this health hazard [ 2, 25 ]. It was evident from this study that level of obesity was significantly associated with the prevalence of diabetes neuropathy. But adults of underweight and normal weight were more exposed to this health problem. Adults of optimal blood pressure were less exposed to the prevalence of diabetes neuropathy. Another important factor for this health problem was the duration of diseases.

The factor analysis identified some of the responsible factors for the prevalence of diabetes neuropathy. These factors were occupation, age, physical inactivity, smoking habit, hypertension, body mass index and family expenditure.

\section{CONClusion}

The information incorporated in the paper was the analytical results observed from the data collected from 960 adults of ages 18 years and above. Out of 960 adults, $16.1 \%$ were patients of diabetes and neuropathy simultaneously. The percentages of males, married persons, Muslim adults, illiterate adults, farmers were 55.2, 69.8, 82.6, 5.6 and 26.6, respectively. All categories of these respondents were more exposed to the prevalence of diabetes and neuropathy.

Prevalence of the disease was more among old people, adults of lower economic conditions, physically inactive adults, smokers and hypertensive people. Though level of obesity was significantly associated with the prevalence of the disease under study, overweight and obese persons were less affected by this health hazard. Habit of taking restaurant food was a risk factor for this disease. The disease was dominant among patients suffering for longer duration. However, the most responsible variable for the prevalence of diabetes neuropathy was occupation of adults. The other responsible variables were higher age, physical inactivity, smoking habit, hypertension, lower level of obesity and lower economic condition.

Diabetes and diseases originated from it cannot be avoided. But steps can be taken as a precaution so that the rate of obese and diabetic patients can be reduced. For this, people can be advised to

(i) To control their body weight by doing some physical work and developing the habit of walking whenever it is possible,

(ii) To avoid restaurant and can food, salty and fatty food and to develop the habit of taking home made food as per as possible,

(iii) To avoid smoking and taking drugs and drinks,

Government, rural and urban health service providers can encourage the people to follow the above suggestions.

\section{REFERENCES}

[1] Akhter, N.(2019): Diabetic peripheral neuropathy : Epidemiology, physiopathology, diagnosis, and treatment; Review Article, Delta Med. Col. Jour., 7(1), 35 - 48.

[2] Vinik, A.; Park, T.S.; Stansberry, K.D. and Pittenger, G.L. (2000): Diabetic neuropathies, Diabetology, 43(8), 957 - 973.

[3] Mitra, T.; Gogas, D.Y.; Abd A. Tahrani; Selvarigh, D. ; Bowling, F.L. and Hassan, F. (2017): diabetic neuropathy : current status and future prospects, Jour. Diabetes Res., Article I.D. 5825971, https://doi.org/10.1155/2017/ 5825971.

[4] Tahrani, A.A. ; Altaf,Q.A.;Piya, M.K. and Barnett, A.H. (20170: Peripheral and autonomic neuropathy in South Asian and White Caucasians with Type-2 diabetes mellitus possible explanations for epidemiological differences, Jour. Diabetes, I.D. 1273789, https:// doi.org/10.1155/2017/ 1273789.

[5] Bansal, V.; Kabita, J. and Misra, U.K. (2006): Diabetic neuropathy, Postgraduate Medical Jour. 82(964), 95 - 100.

[6] Vinik, A. and Zeigler, D.(2007): Diabetic cardiovascular automatic neuropathy, Circulation, 115(3), 387 - 397.

[7] Partanen, J; Niskanen, L. Lehtinen, J.; Marvaala, F.; Siitonen, O. and Uusitupa, M.I.J.(1995): Natural history of peripheral neuropathy in patients with non-insulin dependent diabetes mellitus. New England Jour. Med. 333(2), 89 - 94. 
[8] Tasfaye, S.; Chauturvedi, N. ; Eaton, S.E.M.et al ( 2005): Vascular risk factors and diabetic neuropathy, New England Jour.Med.352(4), $341-431$.

[9] Tahrani, A.A.; Ali, A.;Raymond, N.T. et al (2013): obstructive sleep apnea and diabetic neuropathy : a cohort study, Diabetes Care, 36(11), $3718-3725$.

[10] Rahman, M.M,; Rezvi, A,N.;Uddin,M.N.; Khanam, R.A. Khan, M.A.M.; Khanam, S. (2019): Demographic characteristics of diabetic neuropathy patients attended a tertiary care hospital in Dhaka city, Medicine Today, 31(1), 27 - 30, Doi: https://doi.org/10.3329/medtoday.

[11] Ashoke, S.; Rama, M.; Deepa, R. ; Mohan, V. (2002): prevalence of neuropathy in Type-2 diabetes attending a diabeties centre in South India, Jour. Assoc. Physicians , India, 50, 546 550.

[12] Fardus,J. and Bhuyan, K.C. : Discriminating diabetic patients of some rural and urban areas of Bangladesh: A discriminant analysis approach, Euromediterrean Bio.Jour.2016, 11(9), $134-140$.

[13] WHO (2020): Fact Sheets/Detail/Obesity and Overweight, March 2020.

[14] Jan, A.S.; Yan, Li.; Azusa, H.; KEI, A.; Eamon, D. and O'Brien, E.: Blood pressure measurement anno 2016. Amer Jour Hypertens, 2017, $30(5), \quad 453 \quad-\quad 463$. https://doi:org/10.1093/ajh/hpw 148.

[15] Yotoka,T.(1983): Some criteria for variable selection in factor analysis, Behaviormetrika, 13, $31-45$.

[16] Rusico, J. and Roche, B.( 2012): Determining the number of factors to retain in an exploratory factor analysis using comparison data of known factorial structure, Psychological Assessment, 24(2), 282 - 292,doi:10.1037/a 0025697.

[17] Saquib, N.; Saquib, J.; Ahmed,T,; Khanam,M.A.; Cullen, M.R.(2012): Cardiovascular diseases and type II diabetes in Bangladesh: a systematic review ant meta- analysis of studies between 1995 - 2010, BMC Public Health, 12, 434.

[18] Dinsa, G.D.; Goryakin, Y.; Fumagalli, E. and Suhrcke, M.(2012): Obesity and socioeconomic status in developing countries: A systematic review, Obesity Reviews, 13(11), 1067-79,. Doi:10.1111/j.1467-789X.2012.0101.x.

[19] Bhuyan, K.C. and Fardus,J. ( 2019): Level of obesity and socioeconomic factors of a group of adult people of Bangladesh: A factor analysis approach, Amer, Jour. Data Mining and Knowledge Discovery, 4(1), 8-14, doi: 10.11648/j.ajdmkd.20190401.12.

[20] Bhuyan, K.C. (2019): A note on factor analysis applied in medical research, Archives in Biomed Eng. And Biotech. 1(4), 1-3.

[21] Syed, M.S.; Debra, N.;Muhammad, H.R.; Musa, R; AND Gul, N.(2004): Assessing obesity and overweight in a high mountain Pakistani population, Tropical Medicine and International Health, 9(4), 526-532.

[22] Coatmellec- Taglioni, G. and Ribiere, C.(2003): Factor that influence the risk of hypertension in obese individuals, CurrOpinNephrolHypertens, 12(3), $305-308$.

[23] Kotsis, V.; Stabonli, S.; Bouldin, M.; Low, A.; Toumanidis, S. and Zakopouls, N. (2005): Impact of obesity on 24-hour ambulatory blood pressure and hypertension, 45, $602-607$. doi:10.1161/01.HYP.0000158261.86674.8e.

[24] Shu-Kang Wang.; Wei, Ma.; Shumei, Wang.; Xiang- Ren, Ti.; Hong Ying Jia; and FuzhongXue (2014): Obesity and its relationship with hypertension among adults 50 years and older in Jinan, China, PLOS ONE. https://doi.org/10.1371/journal.pone.0114424.

[25] Boyraz, O. and Saracoglu, M. (2010): The effect of obesity on the assessment of diabetic peripheral neuropathy: Comparison of Michigan physical assessment, Diabetic Research and Clinical Practice, 90(3), 256 260.

Citation: K.C. Bhuyan. Factors Responsible for Diabetes Neuropathy among Bangladeshi Adults. ARC Journal of Diabetes and Endocrinology. 2020; 6(1):7-13. DOI: https://doi.org/10.20431/2455-5983.0601002.

Copyright: (C) 2020 Authors. This is an open-access article distributed under the terms of the Creative Commons Attribution License, which permits unrestricted use, distribution, and reproduction in any medium, provided the original author and source are credited. 